University of Wollongong

Research Online

Faculty of Social Sciences - Papers (Archive) Faculty of Arts, Social Sciences \& Humanities

2008

The big fish strikes again but in a different place: Social comparison theory and children with special needs

Roselyn May Dixon

University of Wollongong, roselyn@uow.edu.au

Marjorie Seaton

University Of Western Sydney

Robert John Dixon

University Of Sydney

Follow this and additional works at: https://ro.uow.edu.au/sspapers

Part of the Education Commons, and the Social and Behavioral Sciences Commons

Research Online is the open access institutional repository for the University of Wollongong. For further information contact the UOW Library: research-pubs@uow.edu.au 


\title{
The big fish strikes again but in a different place: Social comparison theory and children with special needs
}

\author{
Abstract \\ This paper will address the implications of Big-Fish Little Pond Effect (BFLPE) and social comparison \\ theory and school placement of students with special needs. It made use of the PISA data base to \\ determine if type of educational placement had an impact on the academic self-concept with children \\ with special needs. Multiple regression techniques were used to delineate the relationships.

\section{Keywords} \\ comparison, theory, children, special, needs, social, big, fish, place, different, but, again, strikes, ERA2015

\section{Disciplines} \\ Education | Social and Behavioral Sciences

\section{Publication Details} \\ Dixon, R. May., Seaton, M. \& Dixon, R. John. (2008). The big fish strikes again but in a different place: \\ Social comparison theory and children with special needs. International Journal of the Humanities, 5 (12), \\ 151-157.
}




\title{
The Big Fish Strikes again but in a Different Place: Social Comparison Theory and Children with Special Needs
}

\author{
Roselyn May Dixon, University of Wollongong, NSW, AUSTRALIA \\ Marjorie Seaton, University of Western Sydney, AUSTRALIA \\ Robert John Dixon, University of Sydney, Sydney, AUSTRALIA
}

\begin{abstract}
This paper will address the implications of Big-Fish Little Pond Effect (BFLPE) and social comparison theory and school placement of students with special needs. It made use of the PISA data base to determine if type of educational placement had an impact on the academic self-concept with children with special needs. Multiple regression techniques were used to delineate the relationships.
\end{abstract}

Keywords: Social Comparison Theory, Self-Concept, Children with Special Needs

\section{Introduction}

$\mathrm{T}$ HE BIG FISH Little Pond Effect (BFLPE) is related to academic self-concept, one of the principal components of self concept. Theoretically, self-concept is considered to be multidimensional and hierarchical in structure, with academic self-concept, (how one thinks and feels about one's academic ability), one of the principal components (Shavelson, Hubner and Stanton, 1979). Marsh (1987) found that students' academic self-concepts had a direct effect on future educational attainment. In addition, academic self-concept and academic achievement appear to have reciprocal effects. Marsh and Yeung (1997a) not only found that prior self-concepts had an effect on subsequent achievement, but also that academic achievement affected subsequent academic self-concepts. Thus, the promotion of a positive academic self-concept, since it is a major component of self-concept, can be viewed as an important educational goal in itself.

\section{Literature Review}

\section{The Big Fish Little Pond Effect}

In order to understand the formation of academic self-concept it is necessary to examine the role of external frames of reference. That is, similar objective characteristics and achievements can result in quite different self-concepts depending on the frame of reference or standards of comparison that individuals use to evaluate their academic capabilities (Marsh \& Craven, 2000). In an educational context, Marsh (1984a; 1991; Marsh \& Parker, 1984) proposed a frame of reference model called the "Big Fish Little
Pond Effect" (BFLPE) to encapsulate frame of reference effects posited in social comparison theory.

In the theoretical model underlying the BFLPE, Marsh (1984a) hypothesised that students compare their own academic ability with the academic abilities of their peers and use this social comparison as one basis for forming their own academic self-concept. A negative BFLPE occurs when equally able students have lower academic self-concepts when they compare themselves to more able students, and higher academic self-concepts when they compare themselves with less able students. The external frame of reference model hypothesises that students compare their own academic ability, more or less accurately perceived, with the perceptions of the academic ability of other students in their reference group. For example, consider average ability students who attend a high-ability school (i.e., a school where the average ability level of other students is high). Because students' academic skills are below the average of other students in their school, it is predicted that this will lead to academic self-concepts that are below average. Conversely if these students attended a low ability school, then their abilities would be above average in that school. This would lead to academic self-concepts that are above average. Thus, levels of academic self-concepts depend not only on one's academic achievements but also the achievements of peers in the school environment.

In a recent study conducted in Hong Kong, Marsh, Kong, and Hau (2000) demonstrated that the observed BFLPE is the net result of two counter-balancing processes - contrast effects and assimilation effects. Contrast effects (or negative BFLPE) occur when higher school-average achievement levels (the context) lead to lower individual student academic 
self-concepts. Assimilation effects (or positive social comparison, reflected glory effects) occur when higher school-average achievement leads to higher academic self-concepts (Marsh, 1984b). Although implicit in previous explanations of the BFLPE, the concept of the reflected glory effect has not been previously operationalised.

\section{Impact of the Big Fish Little Pond Effect}

Although educational institutions worldwide consider that developing a positive self-concept is an extremely important educational objective (Marsh \& Hau, 2003; Marsh, Köller, \& Baumert, 2001; OECD, 2003), BFLPE research has consistently found that this objective has not always been achieved ( Craven, Marsh \& Print, 2000; Davis, 1966; Marsh \& Hau, 2003; Marsh, Koller, \& Baumert, 2001). For example, Marsh and Parker (1984) assessed the academic self-concept of students from either high ability/high socioeconomic status schools (SES) schools, or low ability/low SES schools. They demonstrated that while academic ability had a positive impact on academic self-concept, the effect of school-average ability on academic self-concept was negative.

Additionally, when primary-aged children in special gifted and talented classes have been assessed, they have shown a decline over time in their academic self-concepts, compared to matched comparison groups (Craven et al., 2000; Marsh et al., 1995). Regrettably, these effects also appear to continue beyond high school. Marsh, Trautwein, Ludtke, Baumert, and Koller (2006) demonstrated that the negative effect of the BFLPE still persisted four years after graduation from high school. Moreover, compared with students of the same ability who attend low-ability schools, students who attend a high ability school also tend to have lower general self-concepts, lower grade point averages, and lower educational and occupational aspirations (Marsh, 1991).

Other researchers have noted that the BFLPE is more pronounced for students of lower ability in academically selective schools (Coleman \& Fults, 1985), while others have suggested that betweenclass ability grouping results in higher academic selfconcepts for students of low-ability, and lower academic self-concepts for students of high-ability (Reuman, 1989). Nevertheless, results generally indicate that the BFLPE is reasonably invariant across ability levels, as interactions between the BFLPE and individual student ability levels are usually small and inconsistent in direction (Marsh \& Craven, 2002; see also Marsh, 2005; Marsh \& Hau, 2003). Thus, the BFLPE has been shown to exist across different age groups and ability levels, and to have an impact on a wide variety of educational outcomes.
The BFLPE has also been investigated cross-culturally. The negative effects of the BFLPE have been found in Israel (Zeidner \& Schleyer, 1998), Germany (Marsh et al., 2001), and Hong Kong (Marsh et al., 2000). Additionally, in the largest cross-cultural study of the BFLPE undertaken to date, Marsh and Hau (2003) examined the effect of individual achievement and school average achievement on academic self-concept in 26 countries. Their findings were three-fold: (1) The BFLPE was evident crossnationally across all 26 countries, the effect of individual achievement on academic self-concept was positive, whereas the effect of school average achievement on academic self-concept was negative in all 26 countries, and significantly so in 24 of the 26 countries; (2) The size of the BFLPE did not vary across ability levels; and (3) The size of the variation between countries was small, even though significant.

In spite of this, research has consistently found that students in academically selective environments have lower academic self-concepts than those students of equal aptitude who attend non-selective schools (Craven et al., 2000; Marsh \& Hau, 2003; Marsh et al., 2001). This contrast effect is the core of the BFLPE. As seen in Figure 1, according to the BFLPE theoretical model, individual ability is positively related to academic self-concept, but a high class or a high school average ability negatively impacts on academic self-concept.

Nevertheless, positive effects can ensue from attending a high ability school: Students can feel pride in being part of such a prestigious school. Known as a reflected-glory or an assimilation effect, this concept has been shown to counterbalance the negative effect of the BFLPE. It has been argued that attending an academically selective school may actually enhance students' academic self-concepts simply because they have gained entry into such an academically elite school. Marsh and his colleagues (Marsh et al., 2001; Marsh, Kong, \& Hau, 2000) have maintained that students who attend high-ability schools might consider that they are intelligent due to the fact that they are in a school with other highly intelligent students.

To empirically demonstrate these effects Marsh, Kong and Hau (2000) conducted a four-year longitudinal study, which evaluated the relationship between assimilation and contrast effects for 7,997 students from 44 high schools in Hong Kong. The results of this study indicated that attending an academically selective school where school-average achievement is high, simultaneously results in a more demanding basis of comparison for students within the school to compare their own accomplishments (that is, a negative contrast effect), and a source of pride for students within the school (that is, a positive 
reflected glory, assimilation effect). As the negative contrast effect was substantially stronger than the counter-balancing assimilation effect, the net effect was negative. The BFLPE was the net result of these two forces. In addition, controlling for reflected-glory effects caused the BFLPE to become even more negative. Thus, this assimilation effect is an important construct to include in BFLPE research.

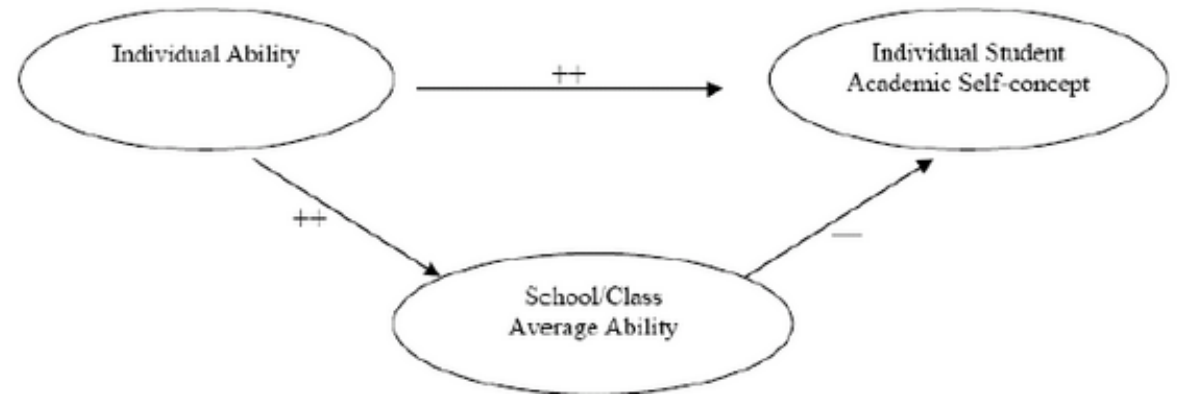

Figure 1: The Big-Fish-Little-Pond Effect (Marsh \& Hau, 2003)

Empirical support for the BFLPE comes from numerous studies (e.g. Marsh, 1994; Marsh \& Craven, 1994; 1997). For example, an early study conducted by Marsh and Parker (1984) examined the path model relationships among achievement, school-average ability and the self-concept responses of Year 6 students. Results revealed that the direct effect of school-average ability upon academic self-concept was negative after individual achievement was controlled for. In contrast, the effects of individual and school-averaged achievement were not statistically significant for non-academic self-concept. Hence, there was clear support for the BFLPE, but only for academic self-concept.

Marsh, Chessor, Craven, and Roche (1995; also see Craven, Marsh \& Print, 2000) designed two studies to test the BFLPE predictions about the effects of participation in full-time "gifted and talented" primary school classes. In both studies, students from gifted and talented programs were matched to students of equal ability from mixed-ability classes. In both studies, students in the gifted and talented program experienced significant declines in three domains of academic self-concept over time and in relation to matched comparison students. In both studies this general pattern of results was reasonably consistent across gender, age, and initial ability. A critical feature of these studies was a multidimensional perspective of self-concept, as the BFLPE predicts that one's educational placement will have a dramatic impact upon academic self-concept but little impact upon nonacademic self-concept. Consistent with a priori predictions based on theory and previous research, participation in gifted and talented programs had a negative effect on academic self-concept and little or no effect on nonacademic self-concept.

Zeidner and Schleyer (1999) tested the BFLPE in a large-scale study based on a nationally representative sample $(n=1020)$ of Israeli gifted students enrolled in either special homogenous classes for the gifted or regular mixed ability classes. Path analyses indicated that gifted students in mixed ability classes reported significantly higher academic self-concepts, lower anxiety and higher school grades than gifted students in special homogenous classes. In sum, research with gifted and talented students suggest that, although, they may experience reflected glory effects through their placement in a selective educational placement, when these students form their selfconcept through comparison with students in their immediate environment, their social comparison are less favourable than their counterparts in regular classes, and thus they experience a deflated academic self-concept.

\section{The Impact of BFLPE on Students with Special Needs}

While there has been a focus on gifted students, there are few studies on impact of BFLPE on students with special needs. Past research has applied social comparison theory to students with learning disabilities, however, there is little empirical research evaluating the BFLPE upon the self-concepts of these students. However, BFLPE theory would predict the opposite to selective school placement for gifted students. The big BFLPE based on social comparison theory predicts that students with special needs will have higher academic self-concepts when in a special school or special class with other students with similar disability or when school average ability is lower (Marsh and Johnston, 1993).

Marsh and Johnston (1993) hypothesised that moving students with learning disabilities from special classes into regular, mixed-ability classes was likely to result in lower academic self-concepts consistent with the predictions based upon social comparison theory and the negative BFLPE. In this context, it is predicted that the contrast and assimilation effects evidenced for gifted and talented students will work in the opposite direction whereby contrast effects will be positive when students with learning disabilities are placed in special homogenous classes 
in that the social comparisons students make in the special classes will be favourable to their academic self-concept (Marsh \& Craven, 2000).

Conversely, the BFLPE predicts that students with mild intellectual disability will have higher academic self-concepts when grouped with other children with similar difficulties. It is argued that placement in a regular class will reduce their academic self-concept because the social comparisons which individuals make with non-disabled reference groups are unfavourable. Children are likely to feel less academically able in comparison with non-disabled children in regular classrooms than with other children with disability in special classes.

\section{Research Studies that Support Impact of BFLPE on Students with Special Needs}

Some Australian research has supported this theoretical position. Hay, Ashman and Van Kraayenoord (1997) study found that academic self-concept improved as students academic scores rose above the class mean but fell if they were below the class mean. In a landmark study, Tracey (2002) compared elementary aged students with mild intellectual disability in special class and regular placement. Those students with mild intellectual disability who were placed in special class were compared to a matched group who were placed in regular class. The students placed in special classes had higher academic selfconcept in Reading and Maths 10 months after placement.

The social environment is believed to play an active role in determining comparison choices and thus self-concept. For instance, Hay, Ashman, and Van Kraayenoord (1997) found that as students' academic scores rose above their class mean their self-concepts increased, and as students' academic scores fell below their class mean their self-concept decreased.

\section{The Present Study}

The BFLPE has been shown to have validity across different age groups, different ability levels and different cultures, but the majority of the research has been conducted with students who are gifted and talented. The study that demonstrated the validity of the BFLPE for students with intellectual disabilities (Tracey, 2002) was conducted with young elementary pupils. There is a need to examine the validity of the BFLPE, with students with special needs, across different age-groups, and different cultures.

The present study aims to ascertain whether the BFLPE is evident in special needs adolescents outside of Australia, across other cultures and in different school systems.

\section{Method}

\section{Participants}

More than a quarter of a million $(276,165)$ fifteenyear-old students from 41 countries participated in the Program of Student Assessment (PISA) conducted by the Organization for Economic Cooperation and Development (OECD) in the year 2003. These students completed paper-and-pencil tests to assess their knowledge and skills in reading, maths, science, and problem solving. In addition, each student completed a questionnaire that assessed a variety of areas including school climate, educational resources in the home, and the central focus of this paper, maths self-concept.

The PISA tests are administered every three years, each year having a different academic focus; for the 2003 administration it was maths. However, not all students completed the maths self-concept items that are central to the current study and so these students were deleted from further analyses. Additionally, to be comparable with the earlier Marsh and Hau (2003) study, schools with 10 participating students or less (917 schools, $8.9 \%$ of total schools) were also deleted from further analyses, as these schools were considered to be too small to be included in multilevel analyses. This resulted in a sample of 265,180 students, in 10,221 schools, across 41 countries.

Of the participants from the original PISA (Program of Student Assessment) (OECD) (270 165 cases), selected 517 students who had done the one hour booklet- (UH in PISA documentation). These students were designated as having special needs in the PISA documentation. Schools that had less than 10 students were deleted. This left 136 students who were the participants in the study.

The participants included students from the following countries,

Belguim - 65 students in 5 schools Hungary-23 students in 2 schools Slovakia-48 students in 4 schools.

\section{Materials}

In the current study, maths self-concept is the response variable, and individual maths achievement (linear and quadratic), school-average achievement, and their cross-products are predictor variables. Maths self-concept was measured using five items, for example, "I get good marks in mathematics" and "I learn quickly in maths". These items were scored on a 4-point Likert scale ranging from 1 (strongly agree) to 4 (strongly disagree). Negative items were reverse scored so that a high score reflects a higher maths self-concept. The reliability of this scale was high, with a Cronbach's alpha of .88 . 
The PISA database does not contain a single maths achievement measure. To prevent obtaining biased population estimates, the PISA (OECD, 2005) database used five plausible values to estimate a student's academic ability. Plausible values are a "representation of the range of abilities a student might reasonably have... Instead of directly estimating a student's ability 2, a probability distribution for a student's 2 is estimated" (OECD, 2005, p. 75). Hence, to obtain more reliable estimates, each analysis was conducted separately with all five plausible values and the results for all parameters used in the analyses were averaged across the five plausible values (refer OECD, 2005).

Maths self-concept was standardised using the five plausible values $(M=0, S D=1)$, across the entire sample, and then created quadratic components for the five plausible values using the standardised terms. Using the final student weight supplied by the PISA database, a school average was calculated for each plausible value (linear) by averaging each one separately within each school. This school average score was not e-standardised thus keeping both the school-average and the plausible values (linear) for maths achievement in the same metric. Crossproducts with school-average were created for each plausible value (linear and quadratic), but were not re-standardised.

The PISA (OECD, 2005) data has a three-level hierarchical structure: countries are at the top of the hierarchy, with schools next, and individual students at the bottom of the hierarchy. To accommodate this hierarchical structure, a multilevel modelling program (Mlwin) was used to analyse these data (refer Rasbash et al., 2004 for details).

\section{Statistical Analysis}

All procedures were conducted using the SPSS program which was then transferred to MLwiN for analyses.

\section{Results}

The results of the study are presented in Table 1 and support the validity of the BFLPE for adolescent students with special needs in European contexts

Table 1:The Effect of Individual Ability and School-Average Ability on the Maths Self-Concepts of Special Needs Students (SE in Brackets)

\begin{tabular}{|l|l|l|l|l|l|l|l|}
\hline \multicolumn{2}{|l|}{ Fixed Effects } & & Random Effects \\
\hline & $\begin{array}{l}\text { Individual } \\
\text { Ability }\end{array}$ & $\begin{array}{l}\text { School-Average } \\
\text { Ability }\end{array}$ & Constant & $\begin{array}{l}\text { Country Ef- } \\
\text { fects }\end{array}$ & $\begin{array}{l}\text { School Ef- } \\
\text { fects }\end{array}$ & $\begin{array}{l}\text { Individual ef- } \\
\text { fects }\end{array}$ \\
\hline $\begin{array}{l}\text { Maths Self- } \\
\text { Concept }\end{array}$ & $0.256^{*}(0.112)$ & $-0.632^{*}(0.254)$ & $-0.134(0.288)$ & $\begin{array}{l}0.003 \\
(0.021)\end{array}$ & $\begin{array}{l}0.082 \\
(0.078)\end{array}$ & $\begin{array}{l}0.777^{*} \\
(0.099)\end{array}$ \\
\hline $\begin{array}{l}\text { Note. All parameter estimates are significant at } 0.05 \text { level when they differ from zero by more than two } \\
\text { standard errors (SEs), depicted by * }\end{array}$
\end{tabular}

A close examination of Table 1 demonstrates 2 significant results. Individual ability has a positive effect on maths self-concept \& school-average ability has a negative effect. So students will have higher maths self-concepts if their ability is higher, but being in a school where the ability level is higher lowers maths self-concept. There were no differences at the country or school levels and there was no significant interaction. The results demonstrate the BFLPE predicted relationship for academic achievement and maths self-concept for adolescent students with special needs as suggested in Figure 1. They also further support the theoretical predictions of BFLPE based on social comparison theory.

\section{Discussion}

This research extends previous research by including adolescents from countries not previously studied and strengthens the external validity of the BFLPE. The results are consistent with BFLPE research which has mainly been concerned with high ability students. School average ability has a negative impact on academic self-concept for students with special needs.

These results have implications for educational policy makers worldwide. Although inclusive placement for students with special needs is driving policy agendas throughout the Western world, these results suggest that placing students in a totally inclusive environment is detrimental to the self-worth of a student with special needs, irrespective of culture. Hence, the BFLPE is not just a symptom of segregated placement of gifted and talented students, but it applies to students everywhere, in any culture. The task of limiting the negative effects of the BFLPE has not been acknowledged by educational policy makers in any culture.

Inclusion is a very powerful ideological movement. However, it has not been supported by a strong empirical research base. It is unlikely that the Inclusion movement will be seriously challenged as such 
the results of this study should lead to efforts to develop intervention strategies to counter the negative impact of the BFLPE. The negative effect of schoolaverage achievement may be confounded with factors such as individual differences in learning, family background, and school climate. These are issues that should be addressed by future research to ascertain if any of these variables reduce or increase the negative effects of the BFLPE. The current investigation could not identify the psychological processes that cause the BFLPE. Future research should examine these processes and develop intervention strategies to counter the negative effects of the BFLPE.

\section{Limitations of the Research}

The major limitation of this study is, because of the data available, it relies totally on correlations between variables, so that it is impossible to infer causality. Also the size of the sample, although quite reasonable when compared to other studies in the special education field ideally should be larger for MlwiN.

\section{Directions for Future Research}

Future research should focus on the examination of processes that cause the BFLPE should lead to intervention strategies that counter the negative impact of the BFLPE for adolescents with special needs who will be placed in inclusive settings.

\section{Conclusion}

Students who experience difficulty learning must contend with repeated academic failures and unfavourable social comparisons. It seems inevitable that given the salience of the school environment that their self-concept is particularly at risk (Heyman, 1990). Given the importance of enhancing selfconcept in itself and the mediating role of selfconcept on other desirable outcomes, it is imperative that researchers and practitioners consider the selfconcepts of students with special needs in all education settings and not slavishly follow popular but empirically unsound ideological and political ideals for these vulnerable students.

\section{References}

Bong, M., \& Skaalvik, E. M. (2003). Academic self-concept and self-efficacy: How different are they really? Educational Psychology Review, 15, 1-40.

Coleman, J. M., \& Fults, B. A. (1985). Special class placement, level of intelligence, and the self-concept of gifted children: A social comparison perspective. Remedial and Special Education, 6, 7-11.

Craven, R. G., Marsh, H. W., \& Print, M. (2000). Gifted, streamed and mixed-ability programs for gifted students: Impact on self-concept, motivation, and achievement. Australian Journal of Education, 44, 51-75.

Hay, I., Ashman, A., and Van Kraayenoord, C. (1997). Investigating the influence of achievement on self-concept using an intra-class design and a comparison of the PASS and SDQ-I self-concept tests. British Journal of Educational Psychology, 67, 311-321.

Heyman, W. (1990). The self-perception of a learning disability and its relationship to academic self-concept and self-esteem. Journal of Learning Disability, 23, 472-475.

Hox, J. (2002). Multilevel analysis: Techniques and applications. New Jersey: Lawrence Erlbaum Associates.

Marsh, H.W. (1984).Self-concept, social comparison and ability grouping: A reply to Kulik and Kulik. American Education Research Journal, 21,799-806.

Marsh, H. (1984b). Self-concept: The application of a frame of reference model to explain paradoxical results. Australian Journal of Psychology, 28, 165-181.

Marsh, H. (1986a). Verbal and maths self-concept: An internal/external frame of reference model. American Educational Research Journal, 23, 129-149

Marsh, H.W. (1987). The big-fish-little-pond-effect on academic self-concept. Journal of Educational Psychology, 79,280295.

Marsh, H. W. (1991). Failure of high ability schools to deliver academic benefits commensurate with their students' ability levels. American Educational Research Journal, 28, 445-480.

Marsh, H.W. (1994). Using Longitudinal Study of 1988 to evaluate theoretical models of self-concept: The self-description questionnaire. Journal of Educational Psychology, 86, 439-456.

Marsh, H. W. (2005). Big-fish-little-pond effect on academic self-concept. German Journal of Educational Psychology, 19, 119-127.

Marsh, H. W., Chessor, D., Craven, R. \& Roche, L. (1995). The effects of gifted and talented programs on academic selfconcept: The big fish strikes again. American Educational Research Journal, 32, 285-319.

Marsh, H., and Craven, R. (2000). Swimming in the school: Expanding the scope of the big fish little pond effect. Conference Proceedings of the 2000 SELF Research Conference. Sydney, Australia: SELF Centre, University of Western Sydney.

Marsh, H. W. \& Craven, R. G. (2002). The pivotal role of frames of reference in academic self-concept formation: the bigfish-little-pond-effect. In F. Pajares \& T. Urdan (Eds.), Adolescence and education (Vol. 2, pp. 83-123). Greenwich, CT: Information Age. 
Marsh, H. W., \& Hau, K. (2003). Big-fish-little-pond-effect on academic self-concept. A cross-cultural (26 country) test of the negative effects of academically selective schools. American Psychologist, 58(5), 364-376.

Marsh, H., and Johnston, C. (1993). Multidimensional self-concepts and frames of reference: Relevance to the exceptional learner. In F. Obiakor, and S. Stile (Eds.), Self-Concept of Exceptional Learners: Current Perspectives for Educators, pp. 72-112. Iowa: Kendall/Hunt Publishing.

Marsh, H. W., Koller, O., \& Baumert, J. (2001). Reunification of East and West German school systems: Longitudinal multilevel modeling study of the big-fish-little-pond effect on academic self-concept. American Educational Research Journal, 38, 321-.

Marsh, H. W., Kong, C. K. \& Hau, K. (2000). Longitudinal multilevel models of the Big-Fish-Little-Pond Effect on academic self-concept: Counterbalancing contrast and reflected glory effects in Hong Kong schools. Journal of Personality and Social Psychology, 78, 337-349.

Marsh, H. W. \& Parker, J. W. (1984). Determinants of student self-concept: Is it better to be a relatively large fish in a small pond even if you don't learn to swim as well? Journal of Personality and Social Psychology, 47(1), 213-231.

Marsh, H.W. \& Rowe, K.J. (1996). The negative effects of school-average ability on academic self-concept: An application of multi-level modelling. Australian Journal of Education, 40, 65-87.

Marsh, H. W., Trautwein, U., Ludtke, O., Baumert, J., \& Koller, 0. (2006). Big Fish Little Pond Effect: Persistent Negative Effects of Selective High Schools on Self-concept after Graduation. University of Western Sydney, SELF Research Centre.

Marsh, H.W., \& Yeung, A.S. (1997). Causal effects of academic self-concept on academic achievement: Structural equation models of longitudinal data. Journal of Educational Psychology, 89, 41-54.

Organisation for Economic Cooperation and Development. (2003). Student engagement at school: A sense of belonging and participation. Paris: Author.

Organisation for Economic Cooperation and Development. (2005). PISA international database (Data Analysis Manual). Paris: Author.

Rasbash, J., Steele, F., Browne, W. \& Prosser, B. (2004). A User's guide to MLwiN - Version 2.0, University of Bristol.

Reuman, D. A. (1989). How social comparison mediates the relation between ability-grouping practices and students' achievement expectancies in mathematics. Journal of Educational Psychology, 81, 178-189.

Schwartz, S. H. \& Bilsky, W. (1990). Toward a theory of the universal content and structure of values: Extensions and cross-cultural replications. Journal of Personality and Social Psychology, 58, 878-891.

Shavelson, R.J., Hubner, J.J. \& Stanton, G.C.(1976) . Self-concept: Validation of construct interpretations. Review of Educational Research, 46,407-441.

Shavelson, R.J., Hubner, J.J. \& Stanton, G.C.(1976) . Self-concept: Validation of construct interpretations. Review of Educational Research, 46,407-441.

Tracey, D.K. (2002). The self-concepts of preadolescents with mild intellectual disability: multidimensionality, measurement, and support for the Big Pond Little Fish Effect. PhD Thesis, University of Western Sydney, Australia

World Bank (n.d.) Country Classification. Retrieved March 24, 2006, from http://web.worldbank.org

Zeidner, M., \& Schleyer, J. (1998). The big-fish-little-pond effect for academic self-concept, test anxiety, and school grades in gifted children. Contemporary Educational Psychology, 24, 305-329.

\title{
About the Authors
}

Dr. Roselyn May Dixon

Dr. Rose Dixon is a special education lecturer at the University of Wollongong, Australia. She has published in the areas of social competence and people with disabilities. She is also involved with Early childhood intervention for children with special needs. She is part of a large research team that is examining culturally relevant education programs in rural and remote Indigenous communities. Another research interest is the application of Social Comparison Theory and Social Cultural Theeory to children with special needs. Dr. Dixon is the Undergraduate supervisor of Special education and the Deputy Director of the Early Childhood program.

\author{
Marjorie Seaton \\ University of Western Sydney, AUSTRALIA
}

Dr. Robert John Dixon

University of Sydney, AUSTRALIA 
Copyright of International Journal of the Humanities is the property of Common Ground Publishing and its content may not be copied or emailed to multiple sites or posted to a listserv without the copyright holder's express written permission. However, users may print, download, or email articles for individual use. 